\title{
COMPARATIVA FOTOGRÁFICA INTERACTIVA COMO DISPOSITIVO DE REVISIÓN DEL PAISAJE. PRÁCTICA ARTÍSTICA: LA ACEQUIA RASCAÑA.
}

Interactive Photographic Comparison As a Landscape Review Device.

Artistic Practice: The Rascaña Canal

\author{
Maria Jose Gutiérrez González \\ mariajosegutirrez@gmail.com \\ Universitat Politècnica de València
}

\section{Introducción}

\section{L}

a investigación que presentamos en este artículo forma parte de una 2018 como parte de nuestra th en las cartografías artísticas como mecanismos para visualizar aquella información ignorada por el discurso oficial. En nuestro caso, adquieren especial importancia los datos vinculados al pasado; queremos mostrar elementos olvidados, o que corren el riesgo de desaparecer. Esta tipología de datos puede convertirse en una estrategia para revisar y replantear nuestro entorno urbano, en constante cambio y evolución, además de ofrecer una alternativa de convivencia con el paisaje rural.

Ante una sociedad postindustrial y posmoderna, este posicionamiento estaría alineado con la idea del respeto y convivencia de los elementos identificativos de un territorio. En estos tiempos, podemos encontrarnos una cultura de la intervención y conservación en los paisajes preexistentes, con 
medidas de sostenibilidad y reciclaje en el entorno. La sociedad ha empezado a ser consciente del importante papel que tienen los rasgos distintivos de un colectivo. De ahí, la búsqueda de nuevos equilibrios ambientales y la voluntad de recreación de la memoria colectiva.

Esta nueva concepción de respeto se ha hecho extensible incluso a las arquitecturas industriales, los ejes fluviales, y cualquier tipo de infraestructuras preexistentes de la sociedad industrial en desuso, y que aún sobreviven milagrosamente en el espacio, frente al constante crecimiento del paradigma urbano imperante. Tener en consideración estos elementos, nos pueden dirigir hacia otro modelo de diseño urbanístico. Esta investigación muestra interés por el paisaje cultural y en especial, por el sistema hidráulico de la huerta valenciana, por su relevancia en la contribución histórica y cultural de este territorio. Una mirada analítica ante su funcionalidad, en relación con el uso sostenible del agua y su consecuente distribución espacial, que adopta este modelo paisajístico tan singular, puede contribuir a los nuevos enfoques de desarrollo urbano en nuestra ciudad, además del reconocimiento de aquellos elementos que construyen identidad en nuestro territorio.

\section{Antecedentes históricos}

A finales del siglo XVIII, empezaron a aflorar nuevos planteamientos sobre la valoración de la naturaleza y su influencia en nosotros. El desarrollo de los postulados románticos, movimiento que tuvo su expansión en todo el siglo XIX, y donde la naturaleza fue un elemento clave para entender el mundo que nos rodeaba, considerando al orden supremo y al hombre de igual manera, fue analizado dentro de ese orden natural al que pertenecía. Además, una importante característica se basaba, en la intención de mezclar la razón y el sentimiento en sus aportaciones. "Una perspectiva cultural que se empeñó en conciliar la razón y el sentimiento, la ciencia y el arte". La naturaleza desde la perspectiva romántica se concibe como comenta Martínez de Pisón “un organismo, como un ser vivo" distanciándose "del modo newtoniano como un mecanismo" (Martínez de Pisón, 2008, p.42). La naturaleza desde la perspectiva romántica se concibe como comenta Martínez de Pisón (2008), “un 
organismo, como un ser vivo" distanciándose "del modo newtoniano como un mecanismo" (p.42). El orden natural se convirtió en el dispositivo para acceder a la verdad, junto con la compresión de la identidad humana. En el ámbito del arte, este nuevo enfoque significó la construcción de una estética de carácter sentimental proyectada en la naturaleza y el paisaje.

Paralelamente, podemos observar en el mundo de la ciencia, se consolidó la exploración a través de grandes viajes, acompañados con estudios precisos de la naturaleza, de tal modo, quedó reforzada la visión de la naturaleza como el orden y significado de todo. En estas fechas empezó a desarrollarse la afición por descubrir lugares, cuya actividad permitía el nacimiento de sentimientos intensos y nuevas interpretaciones en el paisaje. Joan Nogué (2008) apunta la importancia en el siglo XIX, que adopta el viaje y el viajero. "el Wanderer será, en el Romanticismo, una imagen paradigmática para conceptualizar la herencia constitutiva de lo humano" (p.170).

En este período surgió también, la afición del alpinismo, gracias al pionero Horace-Bénédict de Saussure con un libro sobre los Alpes, donde figuraba el Mont Blanc, hasta entonces conocida como la "la montaña maldita" y que empezó a recibir otras valoraciones más positivas. La afición por estos lugares extremos fue inspiración para el desarrollo de la ideas románticas. "La montaña, ignorada, menospreciada o temida con anterioridad, pasa ahora a ser el ámbito predilecto del horizonte romántico" (Ortega, 1999, p.123). Tanto las montañas como los bosques, fueron lugares favoritos de los románticos porque en esos lugares singulares los rasgos naturales quedan ensalzados. En estos lugares buscaron el orden supremo, la armonía en sus formas. Esta actividad muchas veces iba acompañada de la elaboración de epístolas explicativas de los lugares explorados, en ellas quedaba retratado y descrito hasta el mínimo detalle, tanto cuestiones morfológicas del lugar como las emociones y sentimientos generados por el lugar descubierto. Como también, el simple arte de pasear como experiencia estética y de interpretación de la realidad. "Desde el siglo XVII hasta nuestros días la práctica de pasear ha hecho que se encuentre el viandante dotado de gusto pintoresco y entregado al vértigo de lo sublime"(Nogué, 2008, p.61).

A esa conexión directa con la naturaleza, se suma la defensa de la subjetividad como otra característica que definió al romanticismo, como mencionó 
Ortega (1999) "que significa poner en juego todas las capacidades del sujeto, tanto las de índole racional como las de carácter sentimental e imaginativo, es imprescindible para entender correctamente la caracterización unitaria del paisaje" (p.123). Podríamos concretar la idea del paisaje, como puente entre la naturaleza y el hombre. Ya que el paisaje se interioriza como señaló Ortega (1999), de este modo, cuando hablamos del paisaje, supone una interpretación de la naturaleza filtrada por nuestro interior, en definitiva, también hablamos de nosotros en ese paisaje. En conclusión, el romanticismo inauguró el sentimiento moderno del paisaje, e influenció decisivamente en toda la modernidad. Supuso una necesidad de conocimiento más amplio y profundo, ante el modelo uniforme impuesto en las grandes urbes por los postulados racionalistas. Así pues, los nuevos valores propuestos para descubrir el paisaje, permitieron establecer nuevos métodos para comprender las relaciones del hombre con el mundo que le rodeaba.

\section{La geografía moderna}

En este contexto de transformación, se inscribe el nacimiento de la geografía moderna. Alexander von Humboldt fue una figura clave para el nacimiento de la geografía física moderna. Un naturalista que trabajó entre el último tercio del siglo XVIII y la primera mitad del XIX, su visión de la geografía constituyó la fusión de las ideas racionalistas imperantes en la ciencia, junto con los nuevos planteamientos románticos alemanes, tanto de Goethe como de Schelling, además de la influencia de las reflexiones de Kant en la Crítica del Juicio ${ }^{1}$. La geografía moderna constituía la creación de una imagen moderna de la naturaleza más allá del mecanismo. Algunos pensadores consideran que Humboldt estaría más próximo al Renacimiento, por su posicionamiento intermedio:

Conectado con la sensibilidad romántica de su tiempo y con las maneras de entender la naturaleza y el paisaje asociadas a ella, interesado al tiempo

1. La Crítica del Juicio o de la facultad de juzgar o del discernimiento es la última de las tres grandes críticas escritas por Immanuel Kant, publicada en 1790 y reeditada dos veces más en vida del autor. 
en explicar el paisaje y en comprenderlo, en acercarse a lo que el paisaje es y a lo que significa, atento en todo momento, sin disociarlas, a la dimensión científica y a la dimensión sentimental del paisaje. (Martínez de Pisón, 2008, p.62)

Aunque Humboldt tuvo una formación de la naturaleza desde una concepción newtoniana, donde la naturaleza se concebía como una máquina con leyes precisas, donde cada mecanismo quedaba explicado por parámetros físicos y matemáticos. Posteriormente se fue familiarizando con el modelo idealista y romántico de la filosofía de la naturaleza alemana, ya que entró en contacto con el llamado "círculo romántico de Jena" (Corbera, 2014). Estos nuevos métodos de trabajo para acceder al conocimiento planteados por el movimiento romántico, se basaban en la propia esencia del ser, es decir, era un método que abarcaban los aspectos científicos, filosóficos y también artísticos. Esta perspectiva ontológica hace que Humboldt, se encontrara en un estadio intermedio, entre la pura abstracción y el método empírico. En este estadio, la importancia de los sentidos en la construcción del conocimiento fueron vitales en su ciencia (Vitte, Wittgenstein Dias, 2010). Como comentaba Goethe sobre la eficacia de la mirada, "los ojos del espíritu y los ojos del cuerpo deben actuar en una constante y viviente conexión, porque de otro modo se corre el peligro de mirar y, sin embargo, no captar lo que se ve" (Goethe, 2007, p.98).

En consecuencia, la interpretación e investigación que se hace de la naturaleza queda retratada en el paisaje, y este es el mecanismo que nos permitiría conectar a los humanos con lo supremo. Esta interpretación tuvo una gran carga estética, de ahí que los románticos se dieran cuenta del papel tan determinante del arte para acceder al conocimiento. "Sólo desde el arte es posible alcanzar esa naturaleza total, presente en los objetos que la componen, pero que no se revela a cualquier observador" (Corbera, 2014, p.44). Si la naturaleza es el todo, entonces la estética es la mediadora para acceder y comprender esa totalidad viva y organizada. La estética se constituye como comentan Vitte y Wittgenstein Dias (2010): "a partir de conexiones, donde la observación y la contemplación teórica convierten el espectáculo estético en conocimiento científico" (p.73). La nueva geografía recogió la visión planteada por Humboldt, y se mantuvo durante los siguientes siglos XIX y XX. 
Quizá el cambio radical fue el protagonismo que adoptó la figura del hombre en el acceso al conocimiento, como comentaba Corbera (2014): "No se trata sólo de descubrir las concatenaciones de los diversos elementos de la naturaleza, de comprender su unidad por encima de la diversidad, sino también de reconocer el influjo que ésta tiene en la sensibilidad del hombre. Y es aquí donde el aspecto estético y el paisaje entendido desde esta óptica, comienzan a tomar relevancia" (p.49). Esta nueva concepción intentaba ampliar los horizontes del conocimiento. Aquí la geografía y la historia se entrecruzaban. De este modo, la identidad de un territorio lo determinará aspectos morfológicos pero también se sumarán aspectos culturales, como comentaba Martínez de Pisón (2008) "convirtiéndose el paisaje en elemento clave de la construcción nacional" (p.66).

Como conclusión, esa dicotomía entre razón y sentimiento, dimensiones que configuran nuestro conocimiento, aparece en Humboldt con una nueva perspectiva integradora, su capacidad de cohesionar la razón y la sensibilidad a través del hombre, como figura mediadora. Esta confluencia innovadora sin restricciones permitió ampliar y enriquecer los horizontes de la geografía, dotarle de una nueva dimensión para explicar el mundo y nuestra relación con él. Donde el arte, fue la manifestación de esa confluencia. El protagonismo del sentimiento, sentir antes de pensar, donde saber no es simplemente una tarea de ordenar y clasificar, como mencionan Vitte y Wittgenstein Dias (2010): “Concebir que no se puede considerar lo que está fuera sin hacer referencia a sí mismo, que se palpita internamente en el ser” (p.76). Su nuevo planteamiento geográfico y su método de estudio permitió relaciones espaciales dentro del conjunto dinámico, cambiante y complejo de la realidad, en especial con la naturaleza, y con esa visión integradora de las dimensiones subjetivas y objetivas.

\section{El paisajismo creador de identidades}

El concepto del paisaje moderno no es equivalente al concepto de la naturaleza. Podemos decir, que el paisaje es el resultado de la relación que establece el hombre con la naturaleza en un lugar determinado. Como menciona Nogué (2009): “El paisaje no es, pues, sólo la apariencia del territorio, no 
es sólo una figuración, sino una configuración" (p.336). Esa configuración depende de la acción del hombre en sociedad para transformar y adaptar la naturaleza a sus necesidades. La arquitectura y la agricultura suelen ser las actividades principales en la acción del hombre, con estas actividades se suele construir el paisaje rural (Nogué, 2009). De igual modo, los paisajes urbanos son otra modalidad de intervención por parte del hombre en el espacio. Donde las necesidades económicas y los factores culturales suelen ser los responsables de la morfología que adoptan las ciudades, siendo la arquitectura una de las manifestaciones más importantes. Estas características asociadas al paisaje supone una importante carga moral y cultural para el hombre, incluso podemos llegar a categorizar sobre esta relación que es recíproca y vital en la construcción de la identidad. "No hay hombre sin paisaje porque estamos hechos de él” (p.336).

El desarrollo y expansión de la ciudad moderna siempre va acompañado de la destrucción de los vestigios antiguos en la misma. A partir de estas intervenciones también surgen, como consecuencia, unas preocupaciones y sensibilizaciones ante la importancia del paisaje cultural, o como denomina Sauer "geografía cultural". Sauer mantiene la idea de paisaje como una imagen vinculada a un territorio asociado estrechamente a una cultura definida, incluso llega a definir y concretar los elementos claves en esta intervención social, donde: "La cultura es el agente, la naturaleza el medio y el paisaje cultural el resultado" (Nogué, 2008, p.251). Muchas veces corremos el riesgo de la pérdida de la memoria de ciertos lugares construidos, destruir paisaje significa siempre perder cultura.

Una figura relevante en el panorama nacional, fue el escritor Azorín (José Martínez Ruiz, 1873-1967) porque su obra representa uno de los más notables exponentes de la intensa dedicación paisajística en su obra. Como comenta Ortega (2002): “Azorín constituyó una aportación destacada e influyente a la cultura moderna del paisaje en España" (p.130). Claro representante del ideario de la Institución Libre de Enseñanza, y la perspectiva de Francisco Giner de los Ríos, corriente de pensamiento alternativa surgida en el último tercio del siglo XIX en España, la llamada generación del 98. Supuso la visión geográfica moderna del paisaje, con todas sus dimensiones científicas y culturales. Generación que buscó la identidad cultural colectiva, tras los 
últimos cambios y acontecimientos históricos sufridos en el país. El paisaje se convirtió en uno de los refugios más solicitados para su ideario. Sobre todo, la dimensión histórica del paisajismo, y en especial, el rescate de la imagen del pasado en el paisaje es la cualidad que más destacamos aquí sobre el trabajo de Azorín, definido por Ortega (2002): "No es sólo la presencia del pasado en el presente del paisaje lo que busca Azorín; persigue además evocar el pasado mismo del paisaje, acercarse a lo que fue en momentos históricos anteriores" (p.124). Como fuente de investigación de los rasgos distintivos de un colectivo.

\section{La búsqueda de la autenticidad}

En los últimos tiempos, detectamos en la sociedad la reivindicación cada vez más firme, relacionada con la defensa de las identidades singulares; ante la imposición de los espacios regulares y los espacios de flujos, se demanda lo propio, lo auténtico, con el reclamo de unos sólidos valores, ante tanta inconsistencia. "Las personas reclaman su memoria histórica, la pervivencia de sus valores e incluso, el derecho a preservar su propia concepción del espacio y del tiempo" (Nogué, 2010, p.14). El paisaje cultural además contiene una dimensión dual, por un lado, puede contener acepciones sociales y valoraciones científicas, pero, por otro lado, también contempla la relación individual y subjetiva que podemos establecer con él. Las dos dimensiones son compatibles y enriquecen al mismo tiempo a la significación del paisaje. En conclusión, una tendencia para poder escapar del discurso impuesto, sería la búsqueda de los rasgos singulares y una clara alternativa la encontraríamos en la apuesta por las distinciones en los paisajes culturales, ya que nos aportan posibles narrativas como respuesta. En esta tendencia encontramos algunos ejemplos en países europeos ya que han empezado a valorar la importancia de las tramas agrícolas, las zonas de cultivo, dado que nos facilitan conectar directamente con la morfología medieval y renacentista de los campos de aquella época; huertos, herbolarios, campos frutales, esa estructura agrícola dotada de un fuerte valor identitario. "Si el referente son las tramas agrícolas, se trataría de intervenciones que intentan recuperar antiguos sistemas agrarios, es decir, la cuadrícula de los campos de cultivo" (Nogué, 2008, 
p.236). Otra alternativa puede ser la recomposición de anillos verdes en las zonas limítrofes de las ciudades, la reconstrucción de fragmentos de bosques y potenciar los corredores ecológiocos.

En definitiva, la mirada hacia lo local resulta balsámica en estos tiempos confusos y convulsos, por el rescate de tiempos pasados, ya no por la nostalgia de su esplendor, sino más específicamente por el rescate de la autenticidad.

\section{Práctica artística: la acequia ráscaña}

Las observaciones expuestas en relación al concepto del paisaje moderno, a través de la exploración de sus orígenes en la geografía moderna, y su posicionamiento ante la interpretación de la realidad, junto con la influencia del romanticismo en el desarrollo de la significación actual del término, con su reconocimiento como camino para establecer nuevas narrativas de convivencia e identificación con el espacio, despertó en nosotros la necesidad de profundizar en nuestro paisaje cultural próximo, de ahí decidimos evaluar la calidad de su estado por medio de una comparativa fotográfica de distintas épocas. Para ello, elaboramos un ensayo práctico, el cual acabó formalizado en una aplicación interactiva que nos mostraba dicha comparativa. Nos inclinamos por el paisaje que recorre un tramo del trayecto de la acequia Rascaña, es una de las ocho acequias que constituyen la red hidráulica que estructura la huerta de la ciudad de Valencia y sus alrededores, en concreto son las siguientes: Robella, Mestalla, Tormos, Rascaña, Favara, Mislata, Faitanar y Quart. Esta red hidráulica de herencia musulmana fue esencial para el sistema de producción agrícola. Este modelo fue responsable de la morfología de un paisaje, donde además se configuró una red viaria, una arquitectura y una estructura en el cultivo, que dotaría a este territorio de una gran cantidad de elementos singulares.

Hemos escogido la acequia de la Rascaña, porque el estudio del paisaje que acompaña a su trayecto nos permite ejemplificar los cambios sufridos en este territorio, como, por ejemplo, la expansión de las zonas urbanizadas de la ciudad, la desaparición o descuido de la arquitectura vinculada a esta acequia, y también el propio abandono del cultivo de las tierras. 


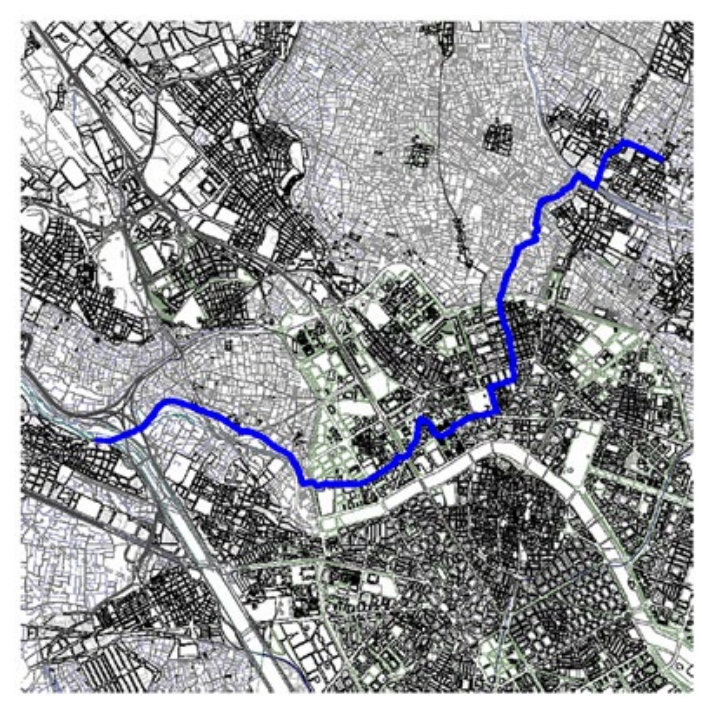

Fig. 1. Imagen de la ficha de la acequia histórica de Rascaña, del Catálogo de bienes y espacios protegidos de naturaleza, Ayuntamiento de Valencia, 2013.

\subsection{Toma de datos}

El material que hemos empleado para establecer la comparativa, se obtuvo a partir de la elaboración de dos secuencias de imágenes. La primera secuencia fue compuesta con fotografías históricas, en concreto, se trataban de las primeras fotografías aéreas verticales que se hicieron en esta zona de los alrededores de Valencia, pertenecientes a la CETFA, Compañía Española de Trabajos Fotogramétricos Aéreos, de 1944, que pudimos consultar en la Cartoteca de la Universidad de Valencia.

Seleccionamos las siguientes fotografías numeradas: $2,3,5,6,7,8$ y 9, para poder componer el tramo del recorrido de la acequia. 


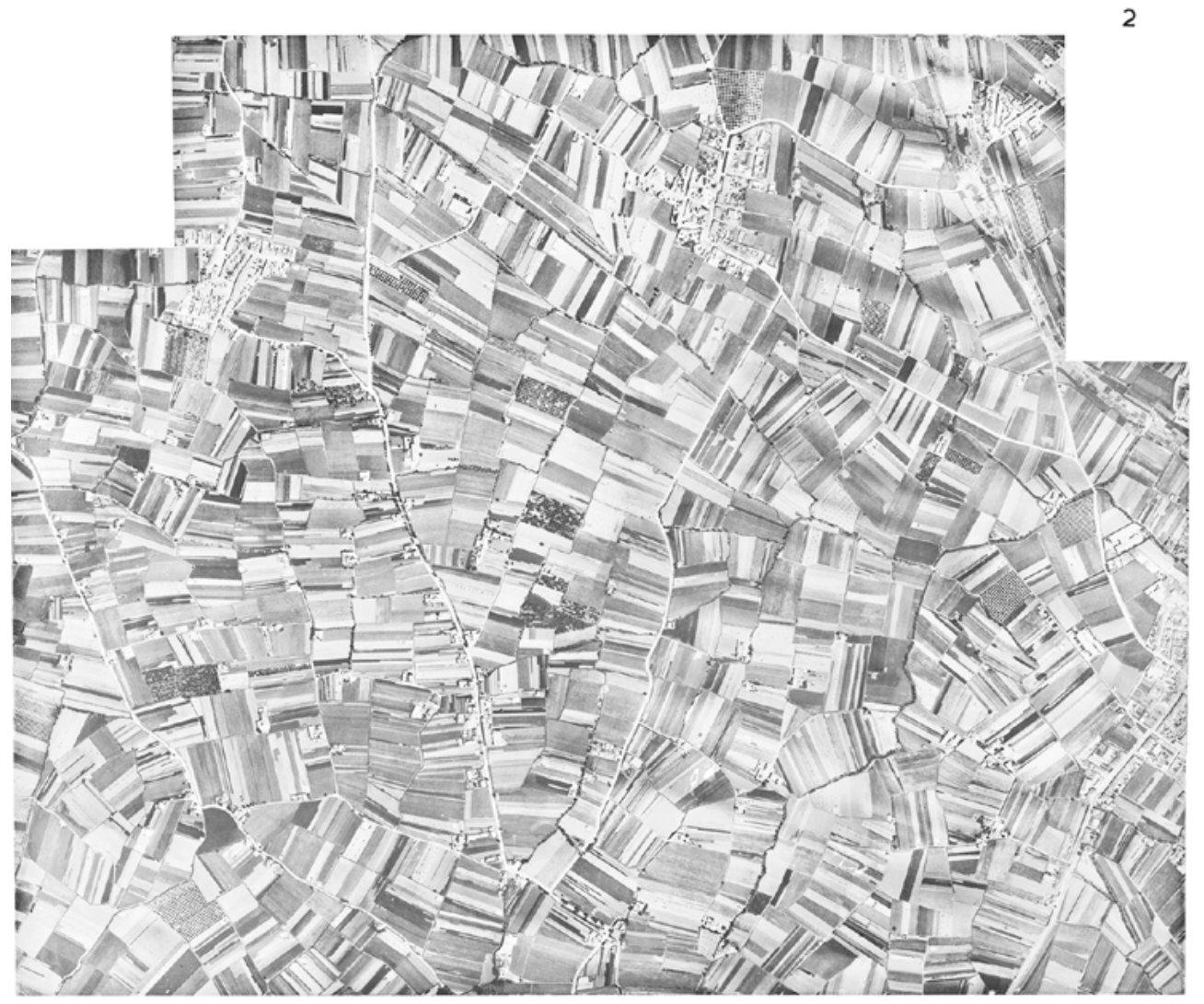

Fig. 2. CETFA, Fotografía aérea vertical, negativo nº 2 de gran formato 1944.

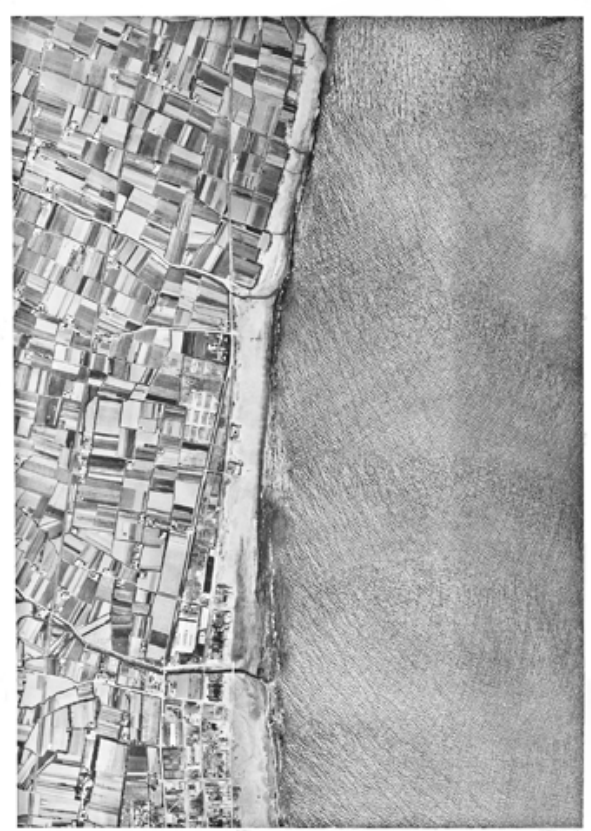

Fig. 3. CETFA, Fotografía aérea vertical, negativo nº 8 de gran formato 1944. 
En cuanto a la segunda secuencia, queríamos recurrir a un registro de imágenes muy conocido en la actualidad, y al mismo tiempo entraba en complicidad con las tomas fotográficas del 1944, en relación al punto de vista cenital, concretamente quedó configurada con capturas de imágenes extraídas de la actual aplicación web de Google Earth, de 2018.

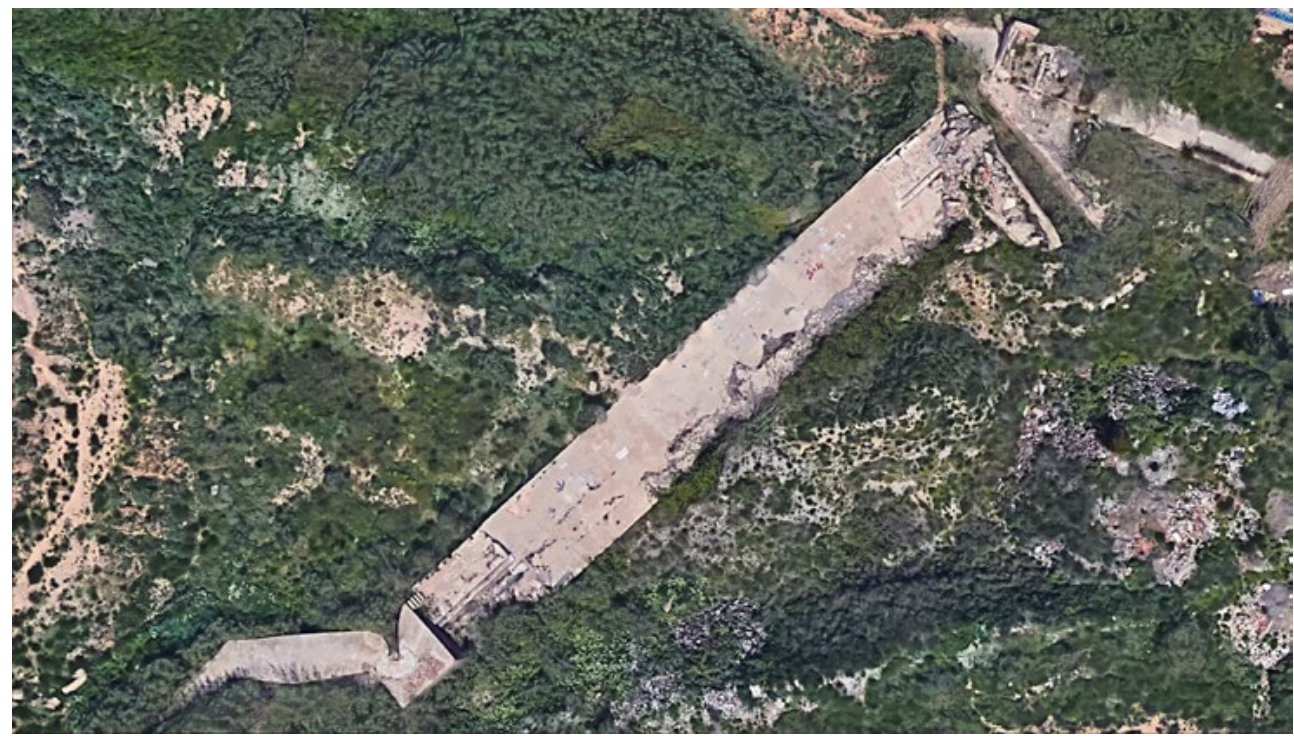

Fig. 3. Imagen obtenida de la aplicación web Google Earth 2018.

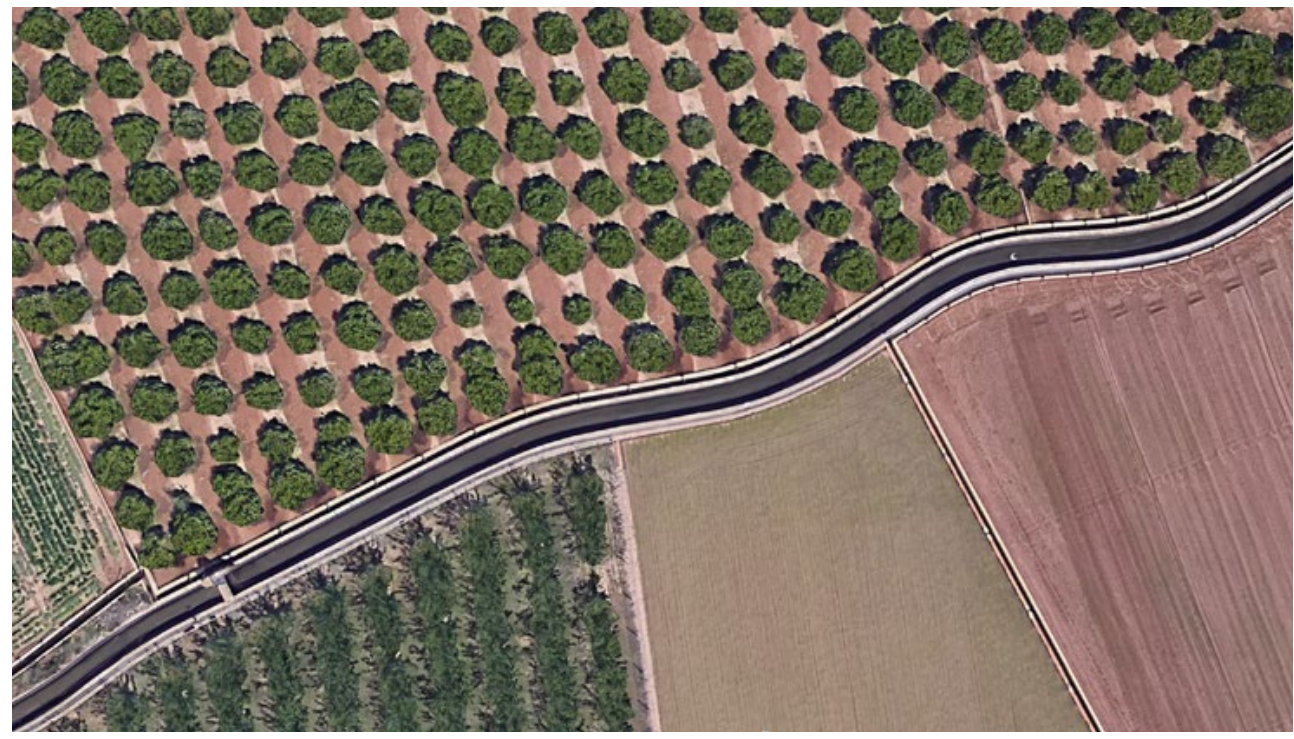

Fig. 4. Imagen obtenida de la aplicación web Google Earth 2018. 


\subsection{Tratamiento de los datos}

Las dos secuencias de imágenes se procesaron a nivel de retoque y montaje para configurar el recorrido de nuestra zona de estudio e interés del trayecto de la acequia, en concreto, la comparativa se definió desde el antiguo azud, (actualmente en desuso tras la construcción del Azud del Repartiment), hasta el municipio de Tavernes Blanques, donde la acequia toma un desvío, en concreto, el brazo de la Riquera, para desembocar en el mar, a través de la acequia de la Mar.

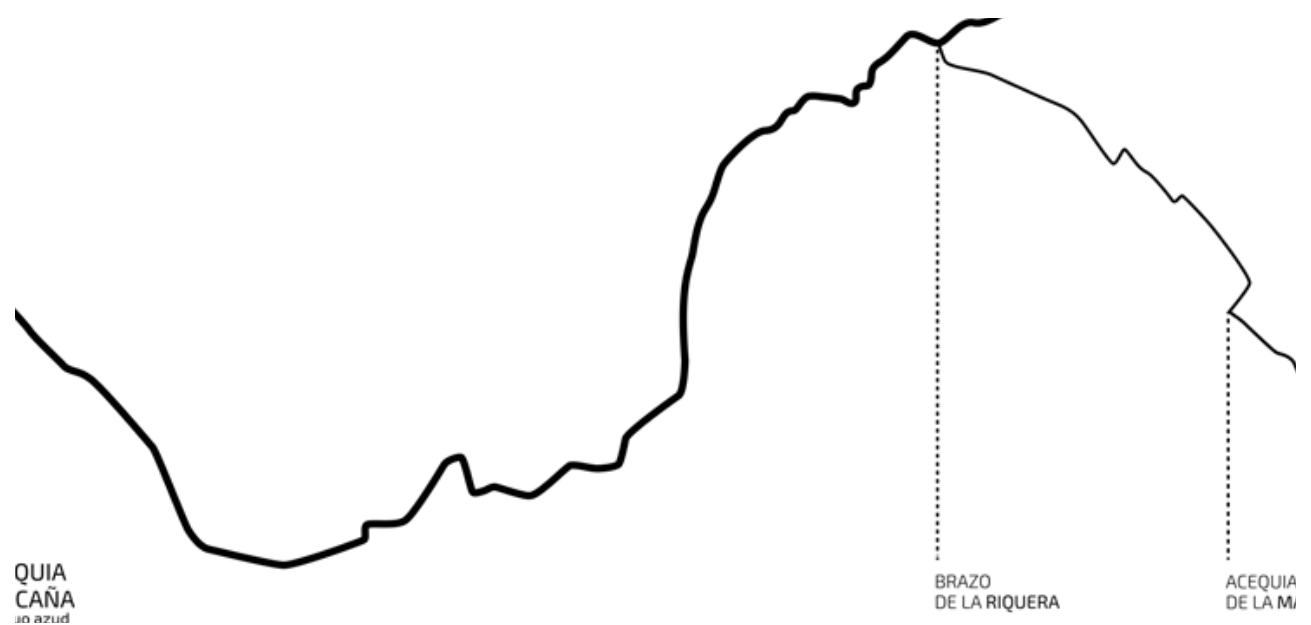

Fig. 6. Diseño de la gráfica que demarca el tramo seleccionado de la acequia, imagen del autor 2018.

En la secuencia correspondiente a las fotografías históricas, tuvimos que realizar tareas de ensamblaje y maquetación en cada fotografía, con software de edición de imagen, con la finalidad de conseguir una composición integra, del tramo descrito anteriormente, del recorrido de la acequia. 

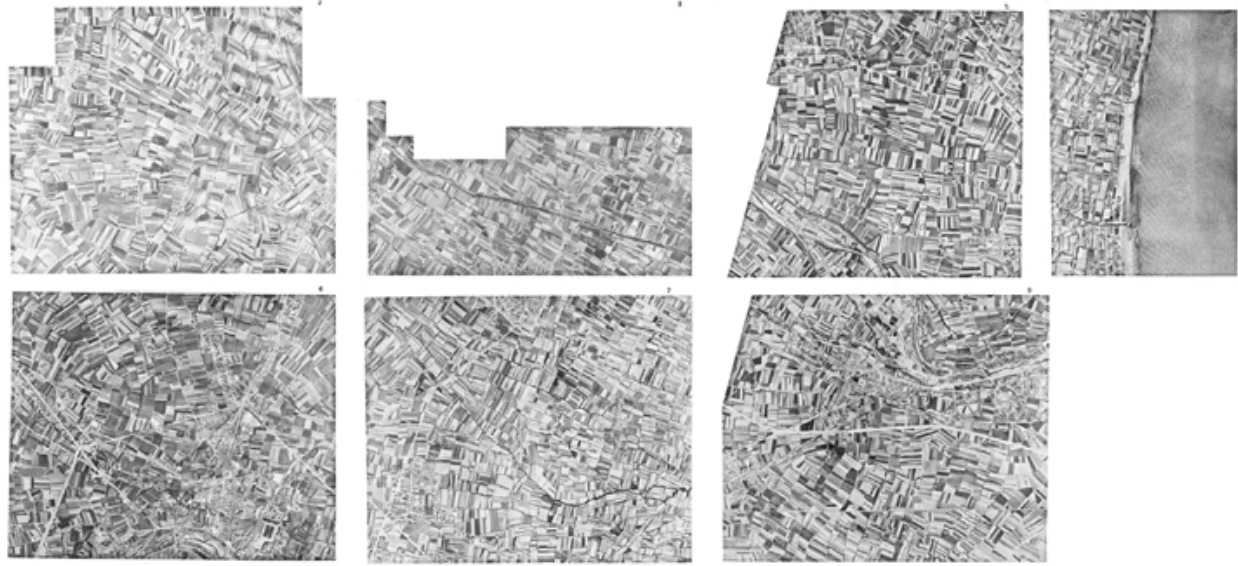

Fig. 7. Fotomontaje de las fotografías seleccionadas de la CETFA, que componen el tramo de la acequia Rascaña.

Posteriormente, realizamos también tareas de edición para homogeneizar el nivel de detalle, tipo de encuadre y tamaño del formato de la imagen, en las dos secuencias con la intención de dotarlas de criterios formales comunes, cualidades necesarias para la elaboración de la aplicación interactiva.

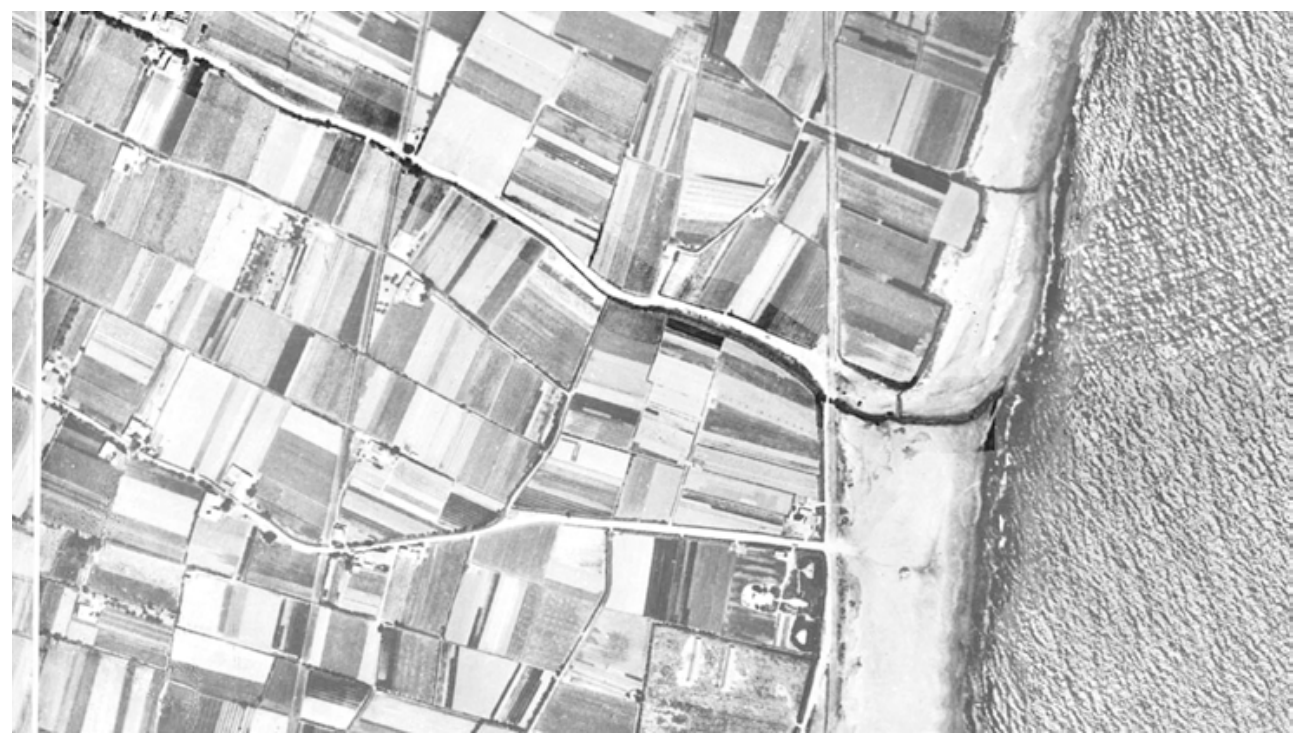

Fig. 8. Imagen de la adaptación y retoque realizado a las fotografías de la CETFA. 


\subsection{Aplicación en Unity}

La comparativa fotográfica se definió en una aplicación interactiva desarrollada con el software Unity, en la cual se diseñó una interfaz en dos dimensiones y con una resolución de 1920 x1080 px. Las fotografías se mostraban escaladas a la misma resolución y a pantalla completa.

Para visualizar la secuencia de imágenes ideamos la interacción usando una botonera deslizante o slider, con la que poder reproducir las imágenes. En la comunidad de desarrolladores de Unity, encontramos componentes que sincronizaban alguna propiedad de transformación de un objeto vinculada con una botonera deslizante, como por ejemplo rotar o escalar, pero no hallamos ninguna propuesta relacionada con el control de una secuencia de imágenes, como era nuestro objetivo. Como consecuencia, nuestra aportación consistió en las siguientes partes:

En primer lugar, generamos un componente llamado ImageManager, para alojar la batería de imágenes de cada una de las secuencias.

Posteriormente a este componente le añadimos el desarrollo de un script llamado ImageAnimation, cuya funcionalidad visualizaba a partir de la interacción del usuario, el renderizado de la secuencia de imágenes como si fuera una reproducción, debido al código que generamos, en el que dispusimos una equivalencia entre el valor de la situación de la botonera slider y la cantidad de número de imágenes de la secuencia fotográfica.

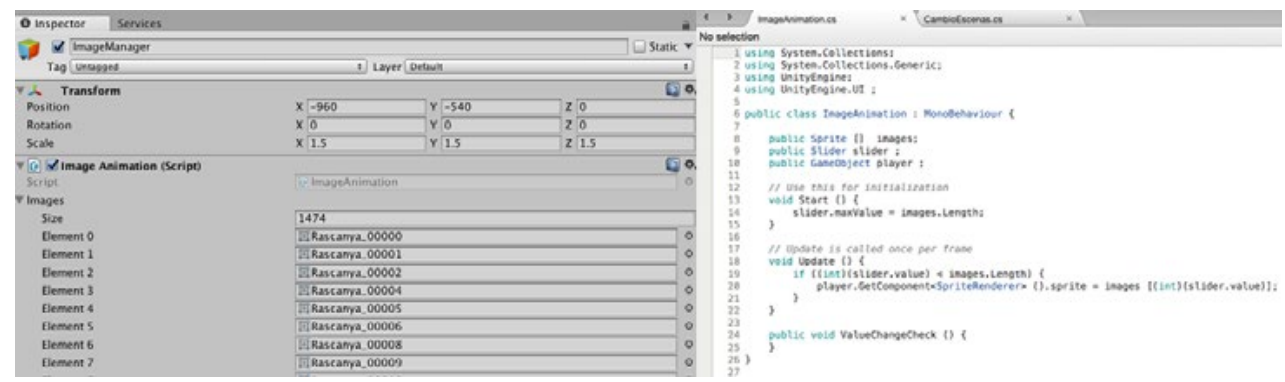

Fig. 9. Fotomontaje del componente ImageManager y el script ImageAnimation, imagen del autor 2018. 
En una primera versión de la aplicación, contemplamos la lectura de la pieza en dos secuencias narrativas diferenciadas, de tal manera que el usuario tras la lectura de las instrucciones de uso, podía pasar a través de un botón de activación, al siguiente nivel, donde accedía a la interacción y reproducción de la secuencia de fotografías de 1944, este recorrido estaba compuesto por 129 imágenes. Desde este nivel, además estaba habilitado otra botonera, en la parte superior derecha de la interfaz, para navegar entre los distintos niveles y así poder pasar a la siguiente, que correspondía a la otra secuencia de imágenes de 2018, compuesta con 239 imágenes.

Para concluir, nos planteamos implementar la comunicación de la comparativa, con la aparición simultánea de una gráfica del recorrido del trayecto de la acequia, además iba acompañada con la información de los elementos más singulares del paisaje, los nombres de los diferentes molinos y su estado de conservación.

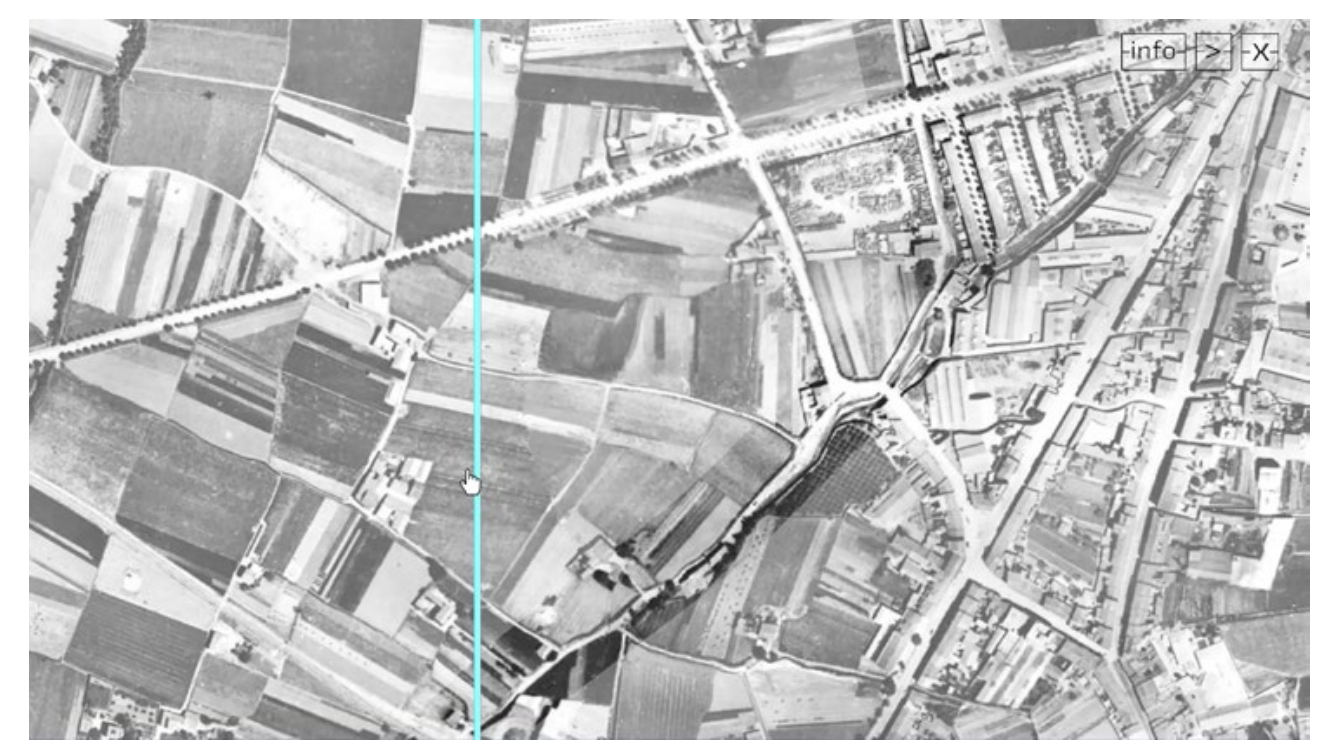

Fig. 10. Imagen de la primera secuencia de la aplicación interactiva, imagen del autor 2018. 


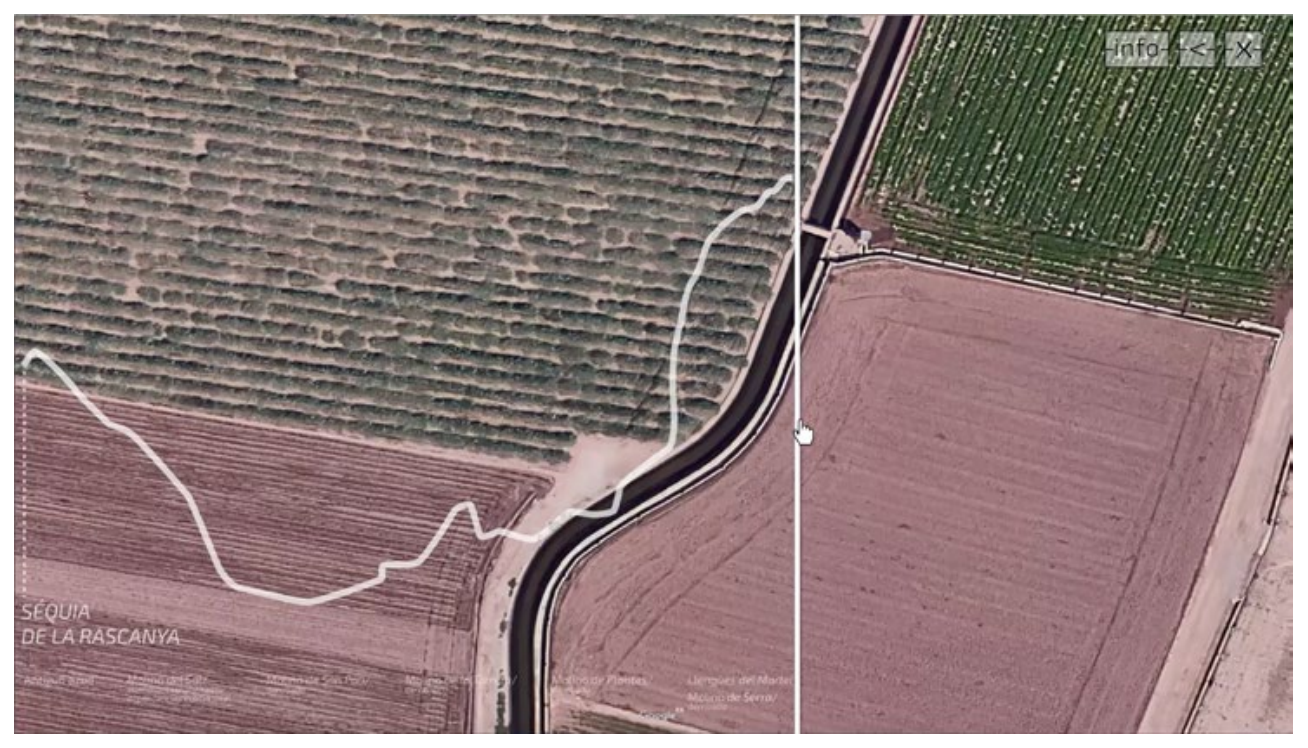

Fig. 11. Imagen de la segunda secuencia de la aplicación interactiva, imagen del autor 2018.

Tras un periodo de testeo y evaluación de la lectura de la aplicación, decidimos corregir errores y como consecuencia, elaborar una nueva versión con la finalidad de alcanzar un diseño más simplificado que nos facilitara una interpretación más clara. Los cambios más significativos fueron los siguiente:

En primer lugar, el diseño se optimizó en la lectura de la comparativa fotográfica, a través de una visualización simultánea de las dos secuencias, de este modo acabaron maquetadas en una misma imagen. Como consecuencia, este cambio supuso una nueva escala de las dos secuencias, así pues, quedaron con un tamaño más reducido y con ello aparecieron unos márgenes en las zonas superior e inferior de la interfaz. Aprovechamos estas modificaciones de tamaño, para mejorar la visualización de la información, de este modo en el margen superior decidimos añadir las fechas de los años, para reforzar la lectura de la comparativa. Por otro lado, el espacio del margen inferior se dejó para contener con mayor claridad, los elementos singulares de la acequia.

En segundo lugar, la otra característica en la nueva versión fue la unificación del número de imágenes en las dos secuencias, en concreto, quedaron definidas con 129 imágenes y de esta forma contribuían a una lectura más equilibrada con respecto a la velocidad de la reproducción. 
Sin embargo, tenemos pendiente un acceso más público de la aplicación para extraer un registro de opiniones e impresiones más amplio y variado de la comunicación y en consecuencia, plantearnos una posible revisión de la aplicación.

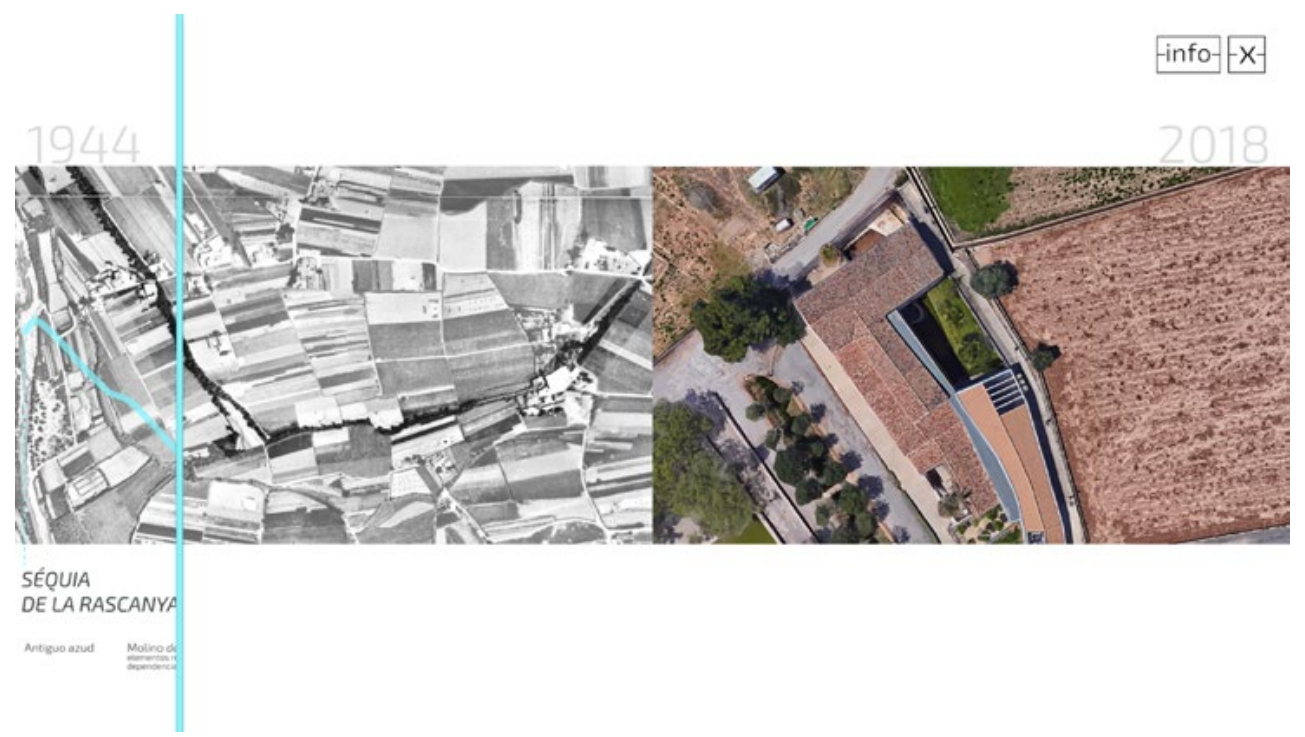

Fig. 12. Imagen de la versión definitiva de la aplicación interactiva, imagen del autor 2018.

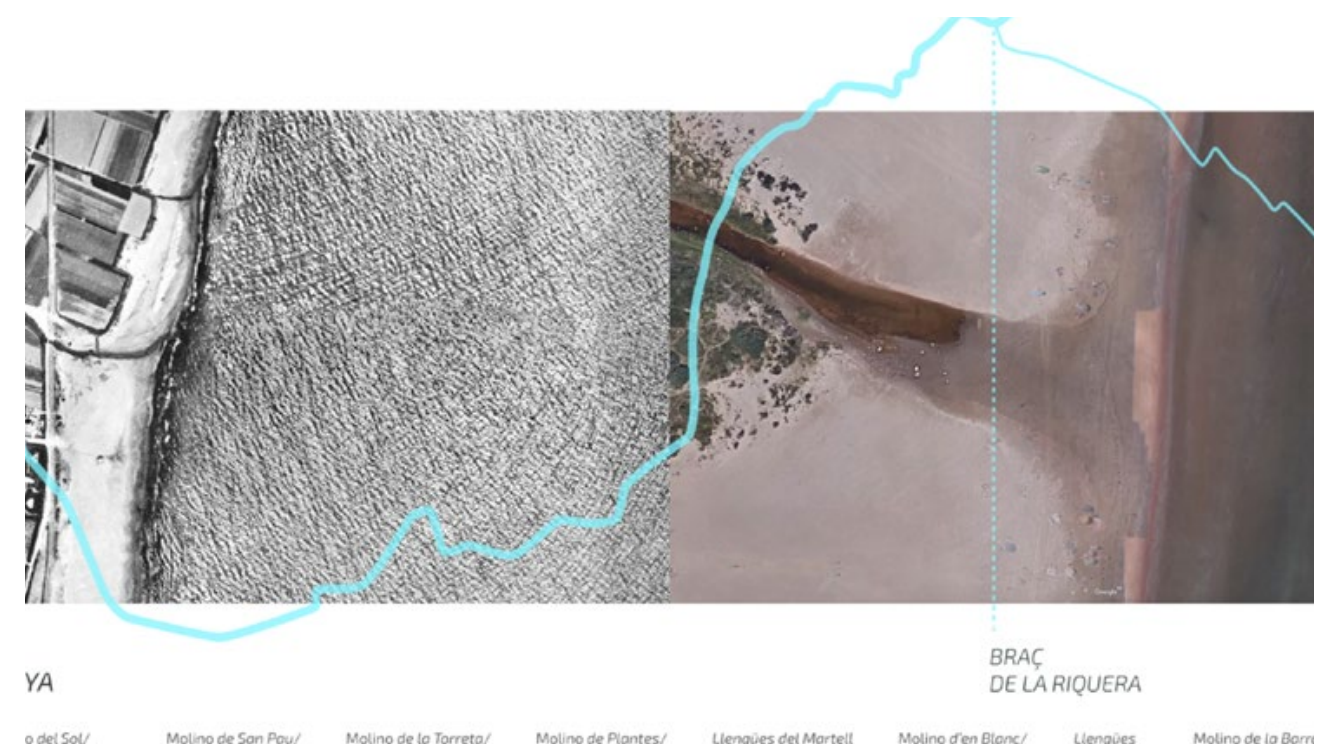

Fig. 13. Imagen de la versión definitiva de la aplicación interactiva, imagen del autor 2018. 


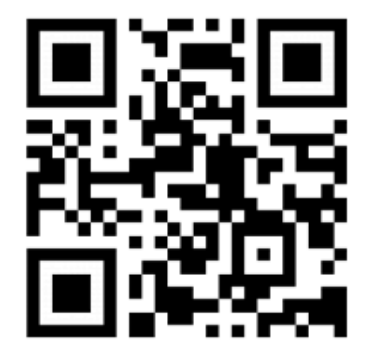

Fig. 14. Código QR que enlaza con un vídeo de simulación de la aplicación interactiva. https://vimeo.com/295128048

\section{Conclusiones}

La comparativa basada en el transcurso del tiempo sobre un paisaje cultural, nos orienta hacia la consideración sobre las distintas relaciones que hemos ido gestando en ese lugar concreto. Podríamos decir que, en la actualidad, este balance asociado al espacio que habitamos, junto con la revisión y rescate de aquellos elementos que aportan significación a un colectivo, se estaría convirtiendo en una necesidad, como una respuesta ante la búsqueda de la singularidad y autenticidad, en nuestras sociedades.

Ante el estado de homogeneidad y fragmentación de los espacios urbanos, que se suma a la pérdida de las zonas públicas que estarían sufriendo nuestras ciudades en el presente siglo, detectamos como la estrategia que revisa la relación con el entorno natural próximo se reafirma como alternativa de futuro. Propuestas de convivencia entre los espacios urbanos y rurales, se convierten en opciones para reflexionar y hacer balance sobre las necesidades de la ciudad, buscando un tratamiento más equilibrado en su expansión y evolución.

Desde este posicionamiento, adquiere valor el rescate de datos del pasado sobre un determinado territorio, ya que pueden constituir una vía de obtención de información relevante para contribuir a esa relación sostenible y armónica con nuestras ciudades y también reforzar la construcción de la identidad colectiva. 
De este modo, entran en consideración, las zonas industriales abandonadas, los vestigios de construcciones de piedra, relatos de otros tiempos y, en definitiva, miradas que nos pueden ampliar la percepción de nuestro entorno más cercano, donde el paisaje cultural, se convierte en un elemento protagonista en esas especulaciones del porvenir, miradas que nos puedan orientar hacia otros modelos de ciudad posible.

\section{Referencias bibliográficas}

Corbera, M. (2014). Ciencia, Naturaleza y Paisaje en Alexander von Humboldt. Boletín de la Asociación de Geógrafos Españoles, 64, 37-64.

Martínez, E. (2008). La Recuperación del paisaje. Una mirada al proceso de retorno desde la geografía española. Madrid, España: Ediciones de la Universidad Autónoma.

Nogué, J.(2008). El Paisaje en la Cultura Contemporánea. Madrid, España: Biblioteca Nueva.S.L.

NoguÉ, J.(2009). La construcción social del paisaje. Madrid, España: Biblioteca Nueva.S.L.

Nogué, J.(2010). Paisatge, territori, i societat civil. Valencia, España: Ediciones $3 i 4$.

Ortega, N. (1999). Romanticismo, paisaje y Geografía. Los relatos de viajes por España en la primera mitad del siglo XIX. ERIA Revista Geográfica, 49, 121-128.

Ortega, N. (2002). Paisaje e identidad nacional en Azorín. Boletín de la Asociación de Geógrafos Españoles, 34, 119-130.

Ortega, N. (1999). Romanticismo, paisaje y Geografía. Los relatos de viajes por España en la primera mitad del siglo XIX. ERIA Revista Geográfica, 49, 121-128.

Vitte, A.C.,Wittgenstein Dias, R. (2010). Alexander von Humboldt y la génesis de la geografía física moderna. HiN. Alexander von Humboldt im Netz, 11(21), 72-85 
